УДК 622.276

\title{
ИССЛЕДОВАНИЕ ФИЛЬТРАЦИОННЫХ ХАРАКТЕРИСТИК И ЭФФЕКТИВНОСТИ ВЫТЕСНЕНИЯ НЕФТИ ПРИ ЗАВОДНЕНИИ МОРСКОГО МЕСТОРОЖДЕНИЯ С ТЯЖЕЛОЙ НЕФТЬЮ
}

Ce Kyн1, xiekun725@163.com

Мэй Цзе 1 , sichuandexuesheng@163.com

Нажису2, Narisu33@126.com

\author{
Су Ченг ${ }^{1}$, \\ 380500259@qq.com
}

Цзян Вэйдун ${ }^{3}$, 1543284194@qq.com

Лу Сянго 1 , 877459272@qq.com

\author{
Ерофеев Владимир Иванович², \\ erofeevvi@mail.ru \\ 1 Северо-Восточный нефтяной университет, \\ Китай, 163000, г. Дацин, ул. Развития, 199. \\ 2 Национальый исследовательский Томский политехнический университет, \\ Россия, 634050, г. Томск, пр. Ленина, 30. \\ 3 CNOOC Ltd., \\ г. Пекин, район Дунчэн, ул. Дунчжимэнвай, 6.
}

Актуальность. По сравнению с традиционными месторождениями нефрти, на морских месторождениях с тяжелой нефртью существует много проблем, связанных с низкой нефртеотдачей заводнения. Если бы мы обладали более глубокими знаниями о фильтрационных характеристиках водной и нефтяной фраз, это было бы очень полезно для улучшения состояния нефтеотдачи заводнения пласта с тяжелой нефтью.

Цель: изучение закономерностей изменения фильтрационных характеристик водной и нефтяной фраз в морском месторождении с тяжелой нефтью, которые очень важны для решения задач разработки нефртяных месторождений и могут представлять руководство для создания моделей численного моделирования.

Методы. Были учтены геологические характеристики пласта, фрлюидные свойства и технология строительства морского нефртяного месторождения Бохай с тяжелой нефтью. Влияние проницаемости керна, вымывания воды и вязкости нефрти на кривую относительной проницаемости и эфффективность вытеснения нефти заводнения было исследовано по методу нестационарного состояния. Изменение внутренней структуры керна представлено с помощью компьютерной томограсрии и ртутного теста давления.

Результаты. С увеличением проницаемости керна относительная проницаемость водной фразы увеличивается, объем охвата водной фразы становится больше, поток двухфазного фрлюида становится шире и конечная нефртеотдача пластов увеличивается. Функция «очистки» и «эрозии», которая образуется от вымывания водой, оказывает влияние на структуру пор керна, увеличивает радиус порового канала керна и проницаемость керна, и ее влияние - на кривую относительной проницаемости и эффрективность вытеснения нефтти такое же, как влияние на увеличение проницаемости. С увеличением вязкости нефти способность регулирования подвижности воды ослабевает в процессе заводнения, объем охвата вытесняемой водной фразы уменьшается, сужается диапазон двухфазного потока, а конечная нефртеотдача уменьшается.

\section{Ключевые слова:}

Морское нефртяное месторождение, резервуар тяжелой нефтти, заводнение, относительная проницаемость, метод нестационарного состояния, нефтеотдача.

\section{Введение}

Морское нефтяное месторождение Бохай богато запасами тяжелой нефти $[1,2]$, но под влиянием осадочной среды в процессе разработки месторождения тяжелой нефти возникают такие проблемы, как высокая вязкость нефти, несцементированная структура породы и большая неоднородность пласта, которые приводят к долгосрочному низкому эффекту разработки заводнения, а степень извлечения нефти обычно составляет менее 18 \% [3-6]. В связи с этим важно исследовать механизм фильтрации пластовых флюидов в процессе разработки нефтяного месторождения с тяжёлой нефтью при заводнении, чтобы установить рациональный план разработки и принять меры по повышению нефтеотдачи пластов. В процессе разработки месторождения при заводнении очень важно использовать кривую относительной проницаемости нефтяной и водной фаз для уточнения характеристик фильтрации нефти и воды в пласт для повышения нефтеотдачи пластов [7-11]. Однако из-за несцементированной структуры породы коллектора отбор керна на морском месторождении затруднен и керн становится рыхлым песком после того, как его извлекают из пласта на поверхность. Исследования относительной проницаемости нефтяной и водной фаз с использованием природных кернов в основном сосредоточены на обычных песчаниковых, низкопроницаемых 
и плотных коллекторах, однако очень мало исследований относительной проницаемости нефтяной и водной фаз и эффективности вытеснения нефти при заводнении на морских месторождениях с тяжелой нефтью [12-15]. Кроме того, в отличие от режима разработки наземного нефтяного месторождения, морское нефтяное месторождение ограничено сроком службы платформы и эксплуатационными расходами и обычно принимается режим «сильной закачки и сильной добычи». Ежедневный объем закачки одной скважины может достигать тысяч кубометров. Таким образом, вымывание закачиваемой воды на несцементированную структуру породы приведет к значительному увеличению проницаемости пласта, что сильно влияет на фильтрационные характеристики двухфазного флюида [16-19]. В данной работе были учтены геологические характеристики пласта, флюидные свойства и технология строительства морского нефтяного месторождения Бохай с тяжелой нефтью. На основе разработки искусственных кернов с рыхлой структурой песчаника на морских нефтяных месторождениях оптимизируется метод испытаний кривой относительной проницаемости. По методу нестационарного состояния было исследовано влияние проницаемости керна, вымывания воды и вязкости нефти на кривую относительной проницаемости и эффективность вытеснения нефти заводнением. Результаты исследования дают теоретическое обоснование работ по повышению нефтеотдачи пластов тяжелой нефти.

\section{Экспериментальная часть}

Материаль для эксперимента. Нефть, использованная в экспериментах, представляет собой дегазированную нефть из месторождения SZ36-1, смешанную с керосином. Вязкость нефти при температуре пласта $65{ }^{\circ} \mathrm{C}$ составляла 70, 310, 530, 840, 1210 и $1580 \mathrm{мПа}$ с. В качестве технологической воды для проведения опытов использовалась нагнетаемая пластовая вода нефтяного месторождения SZ36-1. Общая степень минерализации составляла 9947,8 мг/л, массовые концентрации ионов представлены в табл. 1.

Таблица 1. Анализ качества воды

Table 1. Water quality analysis

\begin{tabular}{|c|c|c|c|c|c|c|c|c|}
\hline $\begin{array}{c}\text { Состав ионов } \\
\text { Ionic composition }\end{array}$ & $\mathrm{Ca}^{2+}$ & $\mathrm{Mg}^{2+}$ & $\mathrm{Na}^{+}$ & $\mathrm{CO}_{3}{ }^{2-}$ & $\mathrm{HCO}_{3}^{-}$ & $\mathrm{Cl}^{-}$ & $\mathrm{SO}_{4}{ }^{2-}$ & $\begin{array}{l}\text { Общая степень минерализации } \\
\text { General degree of mineralization }\end{array}$ \\
\hline $\begin{array}{l}\text { Массовая концентрация иона (мг/л) } \\
\text { Mass concentration of ion }(\mathrm{mg} / \mathrm{L})\end{array}$ & 275,6 & 305,5 & 3090,2 & 0,0 & 311,5 & 5879,7 & 85,3 & 9947,8 \\
\hline
\end{tabular}

Keрны. В эксперименте использовались искусственные керны, которые были изготовлены из кварцевых песков и природных нефтяных песков, цементированных эпоксидной смолой. Искусственные керны были разработаны для моделирования структуры неконсолидированного песчаника на морском нефтяном месторождении. Газопроницаемость кернов составляла $1000 \times 10^{-3}, 2500 \times 10^{-3}$ и $5000 \times 10^{-3}$ мкм $^{2}$. Геометрический размер керна: $\varnothing 2,5 \mathrm{~cm} \times 8 \mathrm{~cm}$.

Meтоды и план эксперимента. Относительная проницаемость и эффективность вытеснения нефти двухфазным флюидом в горных породах определялись методом нестационарного состояния по Стандарту газовой промышленности Китайской Народной Республики SY/T 5345-2007.

Экспериментальные этапы метода стационарного состояния заключаются в следующем:

1) При комнатной температуре керн вакуумируется и насыщается водой.

2) При $65{ }^{\circ} \mathrm{C}$ связанную воду, полученную из насыщенной смоделированной нефти, вытесняют нефтью. Затем определяют фазовую проницаемость по нефти при насыщении связанной водой и записывают давление насыщения.

3) При $65^{\circ} \mathrm{C}$ и стабильной обшей скорости закачки жидкости нефть и вода были закачены в керн в соотношении 20:1, 10:1, 5:1, 1:1, 1:5 и 1:10. После того, как поток становился стабильным, записывали перепад давлений, расход нефти и воды на выходе до конца эксперимента.

4) Насыщенность связанной водой различных периодов вычислялась методом материального баланса, а относительная проницаемость двух фаз - методом «J·B· $\mathrm{N} »$, и строили кривую фазовой проницаемости.

Экспериментальные этапы метода нестационарного состояния заключаются в следующем:

1) При комнатной температуре керн вакуумируется и насыщается водой.

2) При $65^{\circ} \mathrm{C}$ связанную воду, полученную из насыщенной смоделированной нефти, вытесняют нефтью. Затем определяют фазовую проницаемость по нефти при насыщении связанной водой и записывают давление насыщения.

3) Для того, чтобы исключить конечный эффект при $65^{\circ} \mathrm{C}$, нефть вытесняют водой с постоянной скоростью 0,8 мл/мин. Фиксируют время появления воды, объем накопленной добычи нефти и накопленной добычи жидкости, перепад давлений между двумя концами керна во время появления воды. В зависимости от объема добычи нефти выбирают соответствующий временной интервал и постепенно расширяют интервал записи. При условии обводненности 100 \% определяют проницаемость водной фазы при остаточной нефтенасыщенности.

4) Насыщенность связанной водой различных периодов вычислялась методом материального баланса, а относительная проницаемость двух фаз - методом «J·B·N», и строили кривую фазовой проницаемости.

5) Вычисляли эффективность вытеснения нефти, и строили кривую зависимости между эффективностью вытеснения нефти и кратностью объема пор закачки воды. 
Anпаратура. Вязкость исследуемых образцов была определена с использованием вискозиметра Брукфилда DV-II, скорость вращения составляла 6 об/мин, а температура испытания $-65{ }^{\circ} \mathrm{C}$. Экспериментальная установка вытесняющего эксперимента состояла из насоса, датчика давления, кернодержателя, ручного насоса, промежуточного контейнера и других деталей. За исключением насоса, остальные детали были помещены в термостат с температурой $65{ }^{\circ} \mathrm{C}$. Сканирующий электронный микроскоп (SEM) Hitachi S-3400N и компьютерная томография высокого разрешения SkyScan1172 использовались для анализа изменений структуры пор керна до и после заводнения, а автоматический прибор для закачки ртути 9520 - для измерения среднего радиуса пор керна.

\section{Результаты и их обсуждение}

Метод испьтания относительной проницаемости. Относительные проницаемости заводнения в условиях различных методов испытаний приведены в табл. 2 и на рис. 1 соответственно.

Из табл. 2 и рис. 1 видно, что тенденция изменения относительной проницаемости заводнения при стационарном и нестационарном методах в основном одинакова, но разница в фазовой проницаемости воды обусловлена различными экспериментальными методами и методами обработки данных. Учитывая большую рабочую нагрузку (сложная операция и длительное время) стационарного метода и склонность к ошибкам в экспериментальном процессе, существующее исследование относительной проницаемости в основном использует нестационарный метод, который имеет много справочных материалов. Кроме того, метод нестационарного состояния может удо- влетворять спрос на испытание эффективности вытеснения. В связи с этим в последующих экспериментах используется метод нестационарного состояния для испытания фазовой проницаемости.

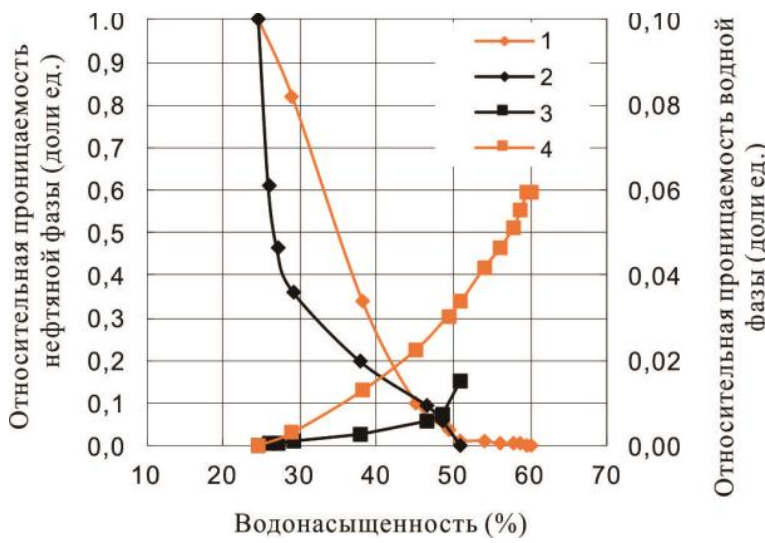

Pис. 1. Кривые относительной проницаемости в условиях различных методов испытаний: 1 - относительная проницаемость нефтяной фазы по методу нестаиионарного состояния; 2 - относительная проницаемость нефтяной фазы по методу стаиионарного состояния; 3 - относительная проницаемость водной фазы по методу стационарного состояния; 4 - относительная пронииаемость водной фазы по методу нестационарного состояния

Fig. 1. Relative permeability curves under different test methods: 1 - oil phase relative permeability by the unsteady state method; 2 - oil phase relative permeability by the steady state method; 3 aqueous phase relative permeability by the steady state method; 4 - aqueous phase relative permeability by the unsteady state method

Таблица 2. Результаты исследования эффективности вытеснения нефти и эксперимента насыщенности

Table 2. Results of oil displacement efficiency and saturation experiment

\begin{tabular}{|c|c|c|c|c|c|}
\hline $\begin{array}{lr} \\
\begin{array}{l}\text { Методы испытаний } \\
\text { Test method }\end{array}\end{array} \begin{array}{r}\text { Параметры } \\
\text { Parameters }\end{array}$ & $\begin{array}{l}\text { Номер } \\
\text { кернов } \\
\text { Core } \\
\text { number }\end{array}$ & $\begin{array}{c}\text { Вязкость нефти } \\
(\text { мПа } \cdot \mathrm{c}) \\
\text { Oil viscosity } \\
(\mathrm{mPa} \cdot \mathrm{s}) \\
\end{array}$ & $\begin{array}{c}\text { Проницаемость } \\
\left(10^{-3} \text { мкм }^{2}\right) \\
\text { Permeability } \\
\left(10^{-3} \mu \mathrm{m}^{2}\right) \\
\end{array}$ & $\begin{array}{c}\text { Насыщенность связан- } \\
\text { ной воды (\%) } \\
\text { Irreducible water } \\
\text { saturation }(\%) \\
\end{array}$ & $\begin{array}{c}\text { Остаточная нефтена- } \\
\text { сыщенность (\%) } \\
\text { Residual oil saturation } \\
(\%) \\
\end{array}$ \\
\hline $\begin{array}{l}\text { Метод стационарного состояния } \\
\text { Steady state method }\end{array}$ & $2500-1$ & 70 & 2486 & 24,7 & 49,0 \\
\hline $\begin{array}{l}\text { Метод нестационарного состояния } \\
\text { Unsteady state method }\end{array}$ & $2500-4$ & 70 & 2512 & 24,6 & 39,8 \\
\hline
\end{tabular}

Таблица 3. Результаты исследования эффективности вытеснения нефти и эксперимента насыщенности

Table 3. Results of the oil displacement efficiency and saturation experiment

\begin{tabular}{|c|c|c|c|c|c|}
\hline $\begin{array}{l}\text { Номер } \\
\text { кернов } \\
\text { Cores } \\
\text { number }\end{array}$ & $\begin{array}{c}\text { Вязкость нефти } \\
\text { (мПа } \mathrm{c}) \\
\text { Oil viscosity } \\
(\mathrm{mPa} \cdot \mathrm{s})\end{array}$ & $\begin{array}{c}\text { Проницаемость } \\
\left(10^{-3} \text { мкм }^{2}\right) \\
\text { Permeability } \\
\left(10^{-3} \mu \mathrm{m}^{2}\right)\end{array}$ & $\begin{array}{c}\text { Насыщенность } \\
\text { связанной воды (\%) } \\
\text { Irreducible water } \\
\text { saturation }(\%)\end{array}$ & $\begin{array}{c}\text { Остаточная нефтенасы- } \\
\text { щенность (\%) } \\
\text { Residual oil saturation (\%) }\end{array}$ & $\begin{array}{c}\text { Эффективность вы- } \\
\text { теснения нефти (\%) } \\
\text { Oil displacement } \\
\text { efficiency }(\%)\end{array}$ \\
\hline $1000-1$ & 70 & 1012 & 28,7 & 44,1 & 38,2 \\
\hline $2500-4$ & 70 & 2512 & 24,6 & 39,8 & 46,7 \\
\hline $5000-6$ & 70 & 4985 & 21,4 & 35,0 & 55,5 \\
\hline
\end{tabular}

Влияние проницаемости керна на относительную проницаемость флюидов и эффективность вытеснения нефти. Результаты исследования эффективности вытеснения нефти заводнения и экспериментов насыщенности в условиях различной проницаемости керна приведены в табл. 3, а кривые относительной проницаемости, зависимость коэффициента извлечения нефти (КИН) и числа PV (PV (pore volume) - объем пор керна) приведены на рис. 2, 3. 


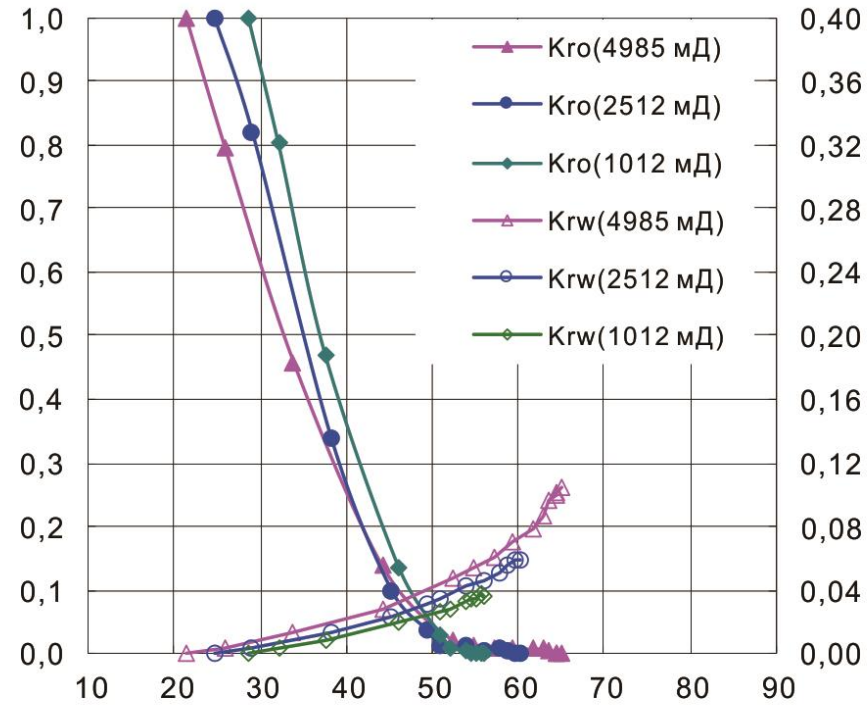

Водонасыщенность (\%)

Рис. 2. Кривые относительной проницаемости в условиях различной проницаемости керна: Кго - нефтяная фаза; Krw - водная фаза

Fig. 2. Relative permeability curves in terms of different permeability core samples: Kro-oil phase; Krw - aqueous phase

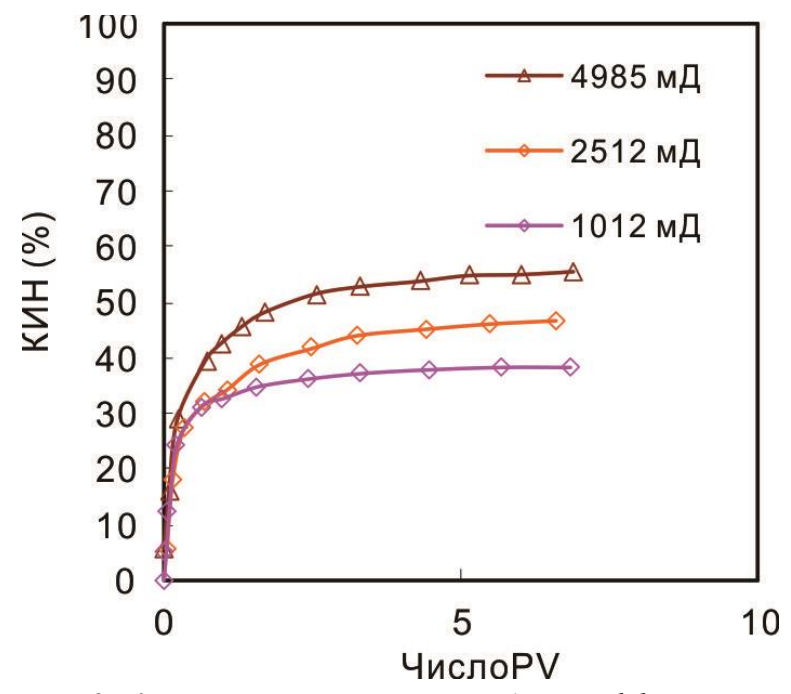

Рис. 3. Кривые зависимости между коэффициентом извлечения нефти и числом $P V$

Fig. 3. Relation curves between oil recovery and $P V$ number

Из табл. 3, рис. 2, 3 видно, что проницаемость керна оказывает влияние на относительную проницаемость нефти и воды и эффективность вытеснения нефти в процессе заводнения водой. В процессе вытеснения воды нефтью для создания связанной воды нефтяная фаза вытесняет водную и занимает поровое пространство. Нефтяная фаза размывает «водную пленку» на поверхности порового канала породы, пытаясь занять поверхность породы. Это приводит к тому, что часть «водной пленки» отделяется. В то же время полярные вещества в нефтяной фазе, такие как нафтеновая кислота, смолы и асфальтены, адсорбируются на поверхности порового канала породы с образованием «нефтяной пленки». С увеличением проницаемости керна средний радиус порового кана- ла увеличивается и нефтяная фаза может входить в большее количество пор керна и вытеснять водную фазу, существующую в порах, что приводит к повышению исходной нефтенасыщенности, уменьшению насыщенности связанной воды и увеличению площади «нефтяной пленки» на поверхности породы. С увеличением площади «нефтяной пленки» на поверхности порового канала породы гидрофильность керна уменьшается и состояние водонефтяного распределения изменяется. Часть связанной воды, первоначально прикрепленной к поверхности порового канала породы в виде «водной пленки», диспергируется в нефтяной фазе в виде капель воды, вызывает эффект Джамина в процессе заводнения и препятствует течению нефтяной фазы, которое приводит к снижению относительной проницаемости нефтяной фазы [20, 21]. Кроме того, за счет увеличения радиуса порового канала уменьшается фильтрационное сопротивление водного раствора в керне, увеличивается текучесть и площадь охвата, а также относительная проницаемость и коэффициент извлечения нефти.

Таким образом, в процессе заводнения с увеличением проницаемости керна относительная проницаемость нефтяной фазы уменьшается, относительная проницаемость водной фазы повышается, насыщенность связанной воды и остаточная нефтенасыщенность уменьшаются, изотоническая точка смещается влево, коэффициент извлечения нефти увеличивается.

Влияние вымыввания водой на относительную проницаемость флюидов и эффективность вытеснения нефти. Искусственный керн вымывали нагнетаемой водой (скорость закачки 1,0 мл/мин, объем закачки 400 PV). Снимки компьютерной томографии и сканирующего электронного микроскопа показаны на рис. 4,5 , соответственно. 


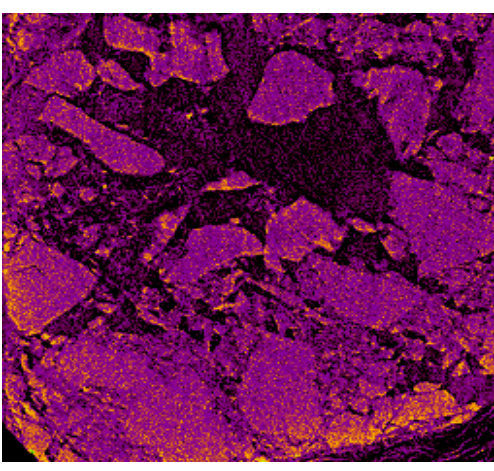

ala

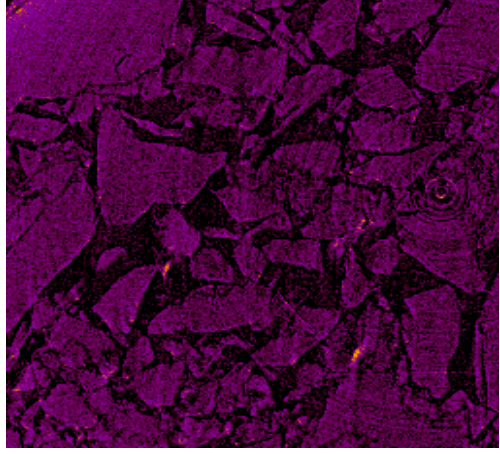

$\sigma / b$

Pис. 4. КТ-снимки керна (а) до и (б) после вымывания водой

Fig. 4. CT images of core (a) before and (b) after water washout

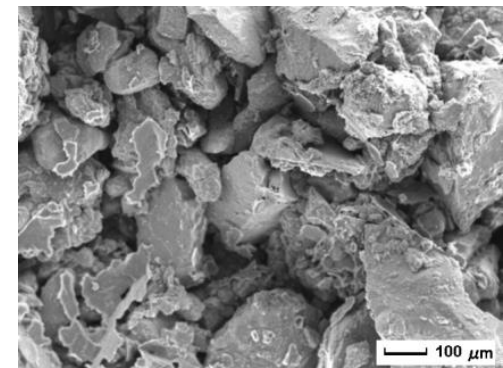

ala

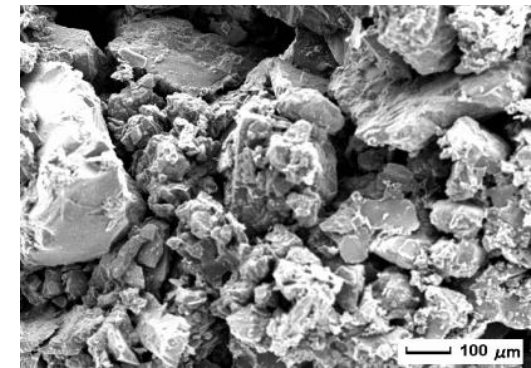

$\sigma / b$

Pис. 5. Снимки сканирующего электронного микроскопа керна (а) до и (б) после вымывания водой

Fig. 5. SEM images of core (a) before and (b) after water washout

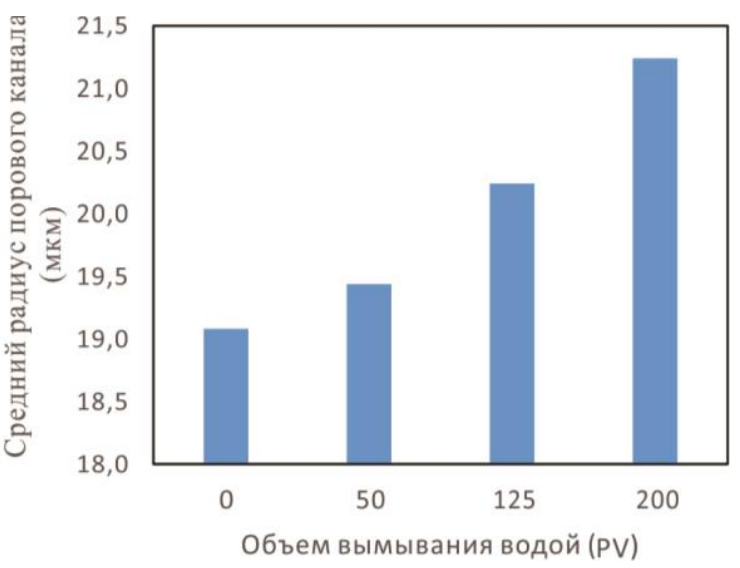

Рис. 6. Средний радиус порового канала кернов до и после вымывания водой

Fig. 6. Average throat radius of core before and after water washout

Из рис. 4, 5 видно, что вымывание водой оказывает влияние на структуру пор породы. Размер пор керна, в которых не было вымывания, невелик и содержит большое количество мелких минеральных остатков. После вымывания водой минеральный остаток в порах керна вымывается и извлекается с миграцией жидкости, а внутренний поровый канал керна становится гладким и чистым. Также нагнетаемая вода оказывает денудационное воздействие на поровый канал керна. Комплексное воздействие вышеуказанных действий заключается в том, что средний радиус порового канала керна увеличивается (рис. 6). Средний радиус порового канала керна увеличивается с повышением объема закачиваемой воды. Таким образом, режим разработки «сильная закачка и сильная добыча» на морском месторождении позволяет значительно повысить проницаемость пластовых пород, поэтому необходимо понимать изменение физических свойств пласта в процессе разработки.

Таблица 4. Результаты исследования эффективности вытеснения нефти и эксперимента насыщенности

Table 4. Results of the oil displacement efficiency and saturation experiment

\begin{tabular}{|c|c|c|c|c|c|c|}
\hline 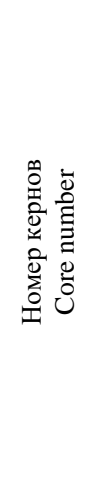 & 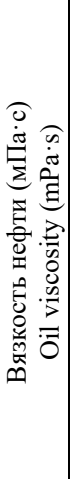 & 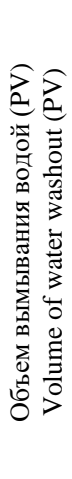 & 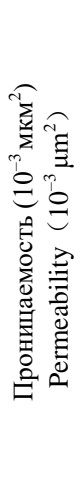 & 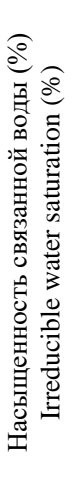 & 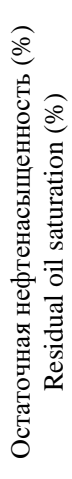 & 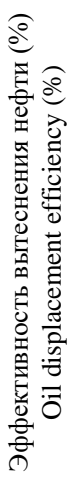 \\
\hline $1000-1$ & 70 & - & 1012 & 28,7 & 44,1 & 38,2 \\
\hline $1000-2$ & 70 & 1000 & 1008 & 26,2 & 35,1 & 43,7 \\
\hline
\end{tabular}

Испытание относительной проницаемости заводнения проводится для керна вымывания водой и керна без вымывания водой соответственно. Результаты исследования эффективности вытеснения нефти и экспериментов насыщенности приведены в табл. 4, а 
кривые относительной проницаемости, зависимость коэффициента извлечения нефти и числа PV приведены на рис. 7,8 .

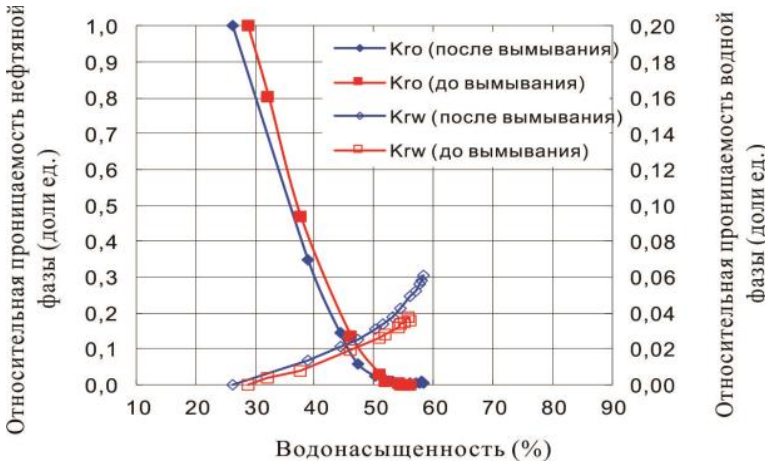

Pис. 7. Кривые относительной проницаемости: Кго нефтяная фаза; Krw - водная фаза

Fig. 7. Relative permeability curves of: Kro - oil phase; Krw-aqueous phase

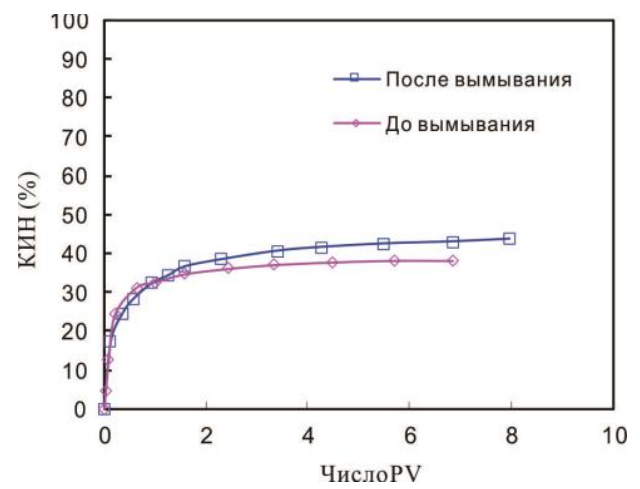

Puc. 8. Кривые зависимости между КИН и числом РV

Fig. 8. Relation curves between oil recovery and PV number

Из табл. 4, рис. 7, 8 видно, что после вымывания водой относительная проницаемость нефтяной фазы уменьшается, относительная проницаемость водной фазы увеличивается, насыщенность связанной воды и остаточная нефтенасыщенность уменьшаются, правая конечная точка кривой смещается вправо, коэффициент извлечения нефти повышается, а изотоническая точка перемещается влево и соответствующее значение относительной проницаемости увеличивается. Долгосрочное вымывание водой может изменить структуру пор керна, а воздействие «очистки» и «эрозии» увеличивают радиус порового канала. Макроскопически проницаемость керна увеличивается, и изменения фазовой проницаемости и эффективности вытеснения нефти такие же, как и при увеличении проницаемости.

Влияние вязкости нефти на относительную проницаемость флюидов и эффективность вытеснения нефти. Результаты исследования эффективности вытеснения нефти заводнением и экспериментов насыщенности в условиях разной вязкости нефти приведены в табл. 5, а кривые относительной проницаемости, зависимость коэффициента извлечения нефти и числа PV приведены на рис. 9, 10.

Из табл. 5, рис. 9, 10 видно, что вязкость нефти оказывает влияние на относительную проницаемость нефти и воды и эффективность вытеснения нефти в процессе заводнения водой. С увеличением вязкости нефти соотношение вязкости нефти и воды растет в процессе создания связанной воды путем закачивания нефти и способность контроля текучести нефтяной фазы повышается, так что создавая большее поровое пространство, можно вытеснить исходную водную фазу из пор. Таким образом, объем охвата нефтяной фазы и первоначальная насыщенность пор нефтью увеличиваются, а насыщенность связанной водой уменьшается. В то же время повышение вязкости нефти может не только усилить воздействие эрозии нефти на «водную пленку» на поверхности породы, но и увеличить количество полярных веществ, прикрепленных к поверхности породы, за счет увеличения содержания нафтеновой кислоты, камеди и асфальтенов в нефтяной фазе. Эти два эффекта проявляются в увеличении площади «нефтяной пленки» на поверхности порового канала породы и ослаблении гидрофильности керна. С ослаблением гидрофильности керна изменяются распределение нефти и воды. Часть связанной воды, первоначально прикрепленной к поверхности порового канала породы в виде «водной пленки», превращается в капли воды и диспергируется в нефтяной фазе, в процессе заводнения образуется «эффект Джамина», который препятствует течению нефтяной фазы. Кроме того, сопротивление потока нефти увеличивается с повышением вязкости, поэтому относительная проницаемость нефтяной фазы будет уменьшаться при заводнении водой. Кроме того, с увеличением вязкости нефти повышается соотношение подвижности вытеснявшей и вытесненной фазы, усиливается явление образования языков обводнения, уменьшается эффективный объем охвата фазы вытеснения, которое приводит к снижению относительной проницаемости нефтяной фазы и эффективности вытеснения нефти.

Таблица 5. Результаты исследования эффективности вытеснения нефти и эксперимента насыщенности

Table 5. Results of the oil displacement efficiency and saturation experiment

\begin{tabular}{|c|c|c|c|c|c|}
\hline $\begin{array}{l}\text { Номер } \\
\text { кернов } \\
\text { Cores } \\
\text { number }\end{array}$ & $\begin{array}{c}\text { Вязкость нефти } \\
\text { (мПа } \mathrm{c}) \\
\text { Oil viscosity } \\
(\mathrm{mPa} \cdot \mathrm{s}) \\
\end{array}$ & $\begin{array}{c}\text { Проницаемость } \\
\left(10^{-3} \text { мкм }^{2}\right) \\
\text { Permeability } \\
\left(10^{-3} \mu \mathrm{m}^{2}\right) \\
\end{array}$ & $\begin{array}{c}\text { Насыщенность свя- } \\
\text { занной воды (\%) } \\
\text { Irreducible water } \\
\text { saturation }(\%) \\
\end{array}$ & $\begin{array}{c}\text { Остаточная нефтенасы- } \\
\text { щенность (\%) } \\
\text { Residual oil saturation (\%) }\end{array}$ & $\begin{array}{c}\text { Эффективность вы- } \\
\text { теснения нефти (\%) } \\
\text { Oil displacement } \\
\text { efficiency }(\%) \\
\end{array}$ \\
\hline $2500-4$ & 70 & 2512 & 24,6 & 39,8 & 46,7 \\
\hline $2500-5$ & 310 & 2515 & 22,5 & 42,0 & 45,8 \\
\hline $2500-6$ & 530 & 2480 & 21,1 & 44,2 & 44,0 \\
\hline $2500-7$ & 840 & 2508 & 19,5 & 48,7 & 39,5 \\
\hline $2500-8$ & 1210 & 2485 & 18,6 & 50,5 & 37,9 \\
\hline $2500-9$ & 1580 & 2480 & 17,7 & 60,7 & 34,4 \\
\hline
\end{tabular}




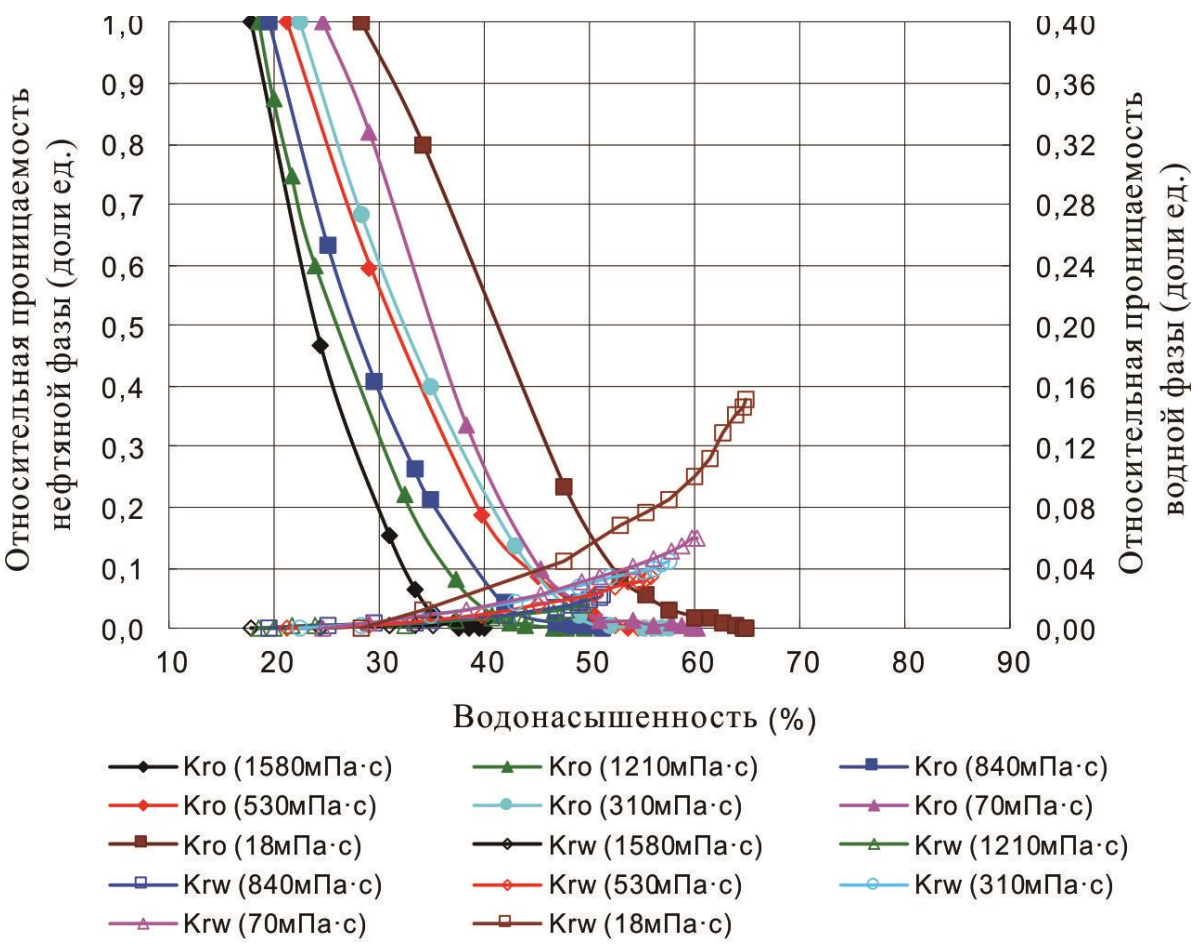

Рис. 9. Кривые относительной проницаемости

Fig. 9. Relative permeability curves

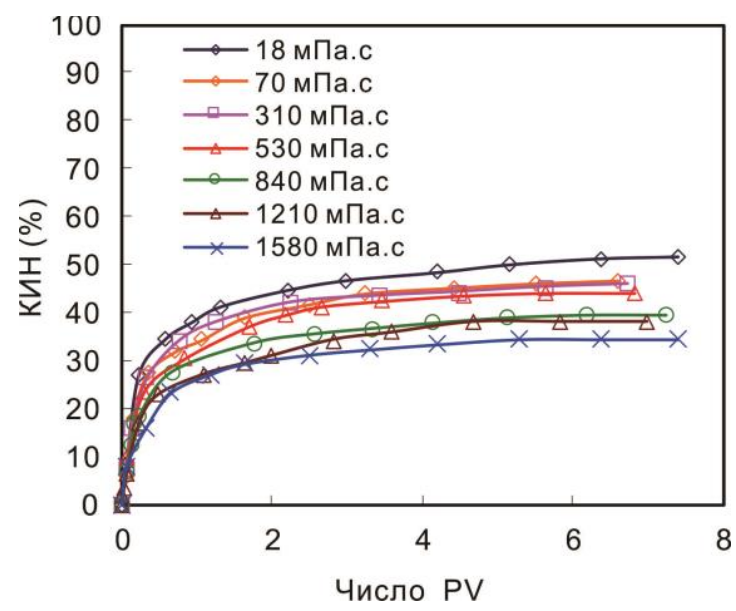

Pис. 10. Кривые зависимости между КИН и числом РV

Fig. 10. Relation curves between oil recovery and $P V$ number

С увеличением вязкости нефти относительная проницаемость нефти и воды уменьшается, насыщенность связанной воды уменьшается, увеличивается остаточная нефтенасыщенность, правая конечная точка кривой и изотоническая точка перемещаются влево, зона пролета двухфазного потока уменьшается и коэффициент извлечения нефти понижается. Таким образом, при разработке месторождения тяжелой нефти вязкость нефти можно снизить с помощью термической обработки, чтобы улучшить текучесть двухфазного потока и увеличить нефтеотдачу пластов.

\section{СПИСОК ЛИТЕРАТУРЫ}

1. Effect of profile-control oil-displacement agent on increasing oil recovery and its mechanism / W. Cao, K. Xie, X. Lu, Y. Liu, Y. Zhang // Fuel. - 2019. - V. 237. - P. 1151-1160.

\section{Выводы}

1. Проницаемость горных пород оказывает значительное влияние на фильтрационные характеристики водонефтяного двухфазного потока. С увеличением проницаемости керна относительная проницаемость водной фазы повышается остаточная нефтенасыщенность уменьшаются, зона пролета двухфазного потока увеличивается и коэффициент извлечения нефти повышается.

2. Функция «очистки» и «эрозии», которая возникает от вымывания водой, оказывает влияние на структуру пор керна, увеличивает радиус порового канала керна и его проницаемость. Ее влияние на кривую относительной проницаемости и эффективность вытеснения нефти такое же, как влияние на увеличение проницаемости.

3. Увеличение вязкости нефти приводит к снижению относительной проницаемости водной и нефтяной фаз, ослаблению способности регулирования текучести вытесняющей фазы, усилению явления образования языков обводнения, уменьшению объема охвата вытесняющей фазы и зоны пролета двухфазного потока и снижению конечной нефтеотдачи пластов.

Работа выполнена при поддержке Фонда естественных наук Китая (№ 51574086, 51834005), национального научно-технического проекта (2016 ZX05058-003-010), Программы поддержки инновационных талантов Китая (ВХ20190065).

2. Investigation on polymer reutilization mechanism of salt-tolerant modified starch on offshore oilfield / C. Dai, S. Yang, X. Wu, Y. Liu, D. Peng, K. Wang, Y. Wu // Energy \& Fuels. - 2016. V. 30. - № 7. - P. 5585-5592. 
3. Matching between the diameter of the aggregates of hydrophobically associating polymers and reservoir pore-throat size during polymer flooding in an offshore oilfield / K. Xie, B. Cao, X. Lu, W. Jiang, Y. Zhang, Q. Li, K. Song, J. Liu, W. Wang, J. Lv, R. Na // Journal of petroleum science and engineering. $-2019 .-$ V. 177. - P. 558-569.

4. Влияние минерализации пластовых вод на физикохимические и фильтрационные характеристики полимерных растворов и гелей для повышения нефтеотдачи пластов / Нажису, В.И. Ерофеев, С. Лу, Ц. Лу, В. Ван, Л. Чжан // Известия Томского политехнического университета. Инжиниринг георесурсов. -2019 . - Т. 330. - № 3. - C. 136-145.

5. Research on new technology for offshore heavy oil thermal recovery with rod pumping / Y. Yu, Z. Chang, Y. Qi, D. Feng // Journal of Petroleum Exploration \& Production Technology. 2018. - V. 8. - № 3. - P. 947-955.

6. Huang S., Cao M., Cheng L. Experimental study on the mechanism of enhanced oil recovery by multi-thermal fluid in offshore heavy oil // International Journal of Heat \& Mass Transfer. - 2018. - V. 122. - P. 1074-1084.

7. Kim C., Lee J. Experimental study on the variation of relative permeability due to clay minerals in low salinity water-flooding // Journal of Petroleum Science and Engineering. - 2017. - V. 157. P. 292-304.

8. Relative permeability variations during low salinity water flooding in carbonate rocks with different mineral compositions / W. Su, Y. Liu, Z. Gao, L. Yang, R. Yang, W. Mcharo, R. Tang // Journal of Dispersion Science and Technology. - 2020. - V. 41. - № 2. P. 227-234.

9. Исследование фильтрационных и реологических свойств полимерного геля для повышения нефтеотдачи пластов / Нажису, В.И. Ерофеев, Ц. Лу, В. Ван // Известия Томского политехнического университета. Инжиниринг георесурсов. 2019. - T. 330. - № 4. - C. 147-157.

10. Classification study on relative permeability curves / P. Gong, B. Liu, J. Zhang, Z. Lv, G. Zhang // World Journal of Engineering and Technology. - 2018. - V. 6. - № 4. - P. 723-737.

11. Relative permeability of gas for unconventional reservoirs / A. Liu, K. Wang, J. Zang, F. Du, A. Zhou // Transport in Porous Media. 2018. - V. 124. - № 1. - P. 289-307.

12. Zolotukhin A., Yazynina I., Shelyago E. Relative permeability hysteresis for oil-water system in hydrophilic rocks // Oil Industry Journal. - 2016. - № 3. - P. 78-80.
13. Wang J., Huiqing L. A novel model and sensitivity analysis for viscoelastic polymer flooding in offshore oilfield // Journal of Industrial and Engineering Chemistry. - 2014. - V. 20. - № 2. P. 656-667.

14. Оптимизация параметров неорганического агента управления профилем на основе силиката натрия для эффективного вытеснения нефти из коллекторов с высокой минерализацией / Нажису, В.И. Ерофеев, С. Лу, Ч. Тянь, Л. Чжан // Известия Томского политехнического университета. Инжиниринг георесурсов. - 2019. - Т. 330. - № 11. - P. 59-68.

15. The research and applications of remaining oil potential tapping in high watered stage for heavy oil reservoir in Bohai / J. Zhang, Z. Liu, L. Wang, Z. Fang, J. Deng // Journal of Geoscience and Environment Protection. - 2018. - V. 6. - № 9. - P. 10-21.

16. Effects of the charge ions strength on the swelling of organicinorganic nanogels / Q. Yu, X. Lu, J. Wang, Q. Guo, L. Niu // Bulletin of Korean Chemistry Society. - 2016. - V. 37. - № 7. P. 1124-1131.

17. Analysis of dynamic imbibition effect of surfactant in microcracks of reservoir at high temperature and low permeability / K. Xie, X. Lu, H. Pan, D. Han, G. Hu, J. Zhang, B. Zhang, B. Cao // SPE Production \&Operations. - 2018. - V. 33. - № 3. - P. 596-606.

18. Wu S., Yan J., Zhao F. Effect of adsorption and deposition of asphaltines in crude oil on wettability and permeability of reservoir rocks // Shiyou Daxue Xuebao. - 2004. - V. 28. - № 1. P. 36-40.

19. Effect of wettability on recovery and relative permeability / Z. Liu, Q. Zheng, Z. Tang, G. Zhang // Oil \& Gas Geology. - 2000. V. 21. - № 2. - P. 148-150.

20. Microscopic modelling of polymer flooding relative permeability curve and its influence factors / J. Li, H. Jiang, M. Chen, H. Gao // Journal of Southwest Petroleum University (Science \& Technology Edition). - 2009. - V. 31. - № 4. - P. 122-126.

21. Variation law of reservoir parameters during water flooding in Dagang oilfield / L. Guo, Y. Wang, W. Liu, C. Zhang, W. Liu, T. Liu // Petroleum geology \& experiment. - 2006. - V. 28. № 1. - P. 86-91.

Поступила 19.08.2020 г.

\section{Информация об авторах}

$\boldsymbol{C} \boldsymbol{K} \boldsymbol{K \boldsymbol { \mu }}$, доктор технических наук, доцент Института нефтегазового дела Северо-Восточного нефтяного университета.

Мэй Цзе, магистр ключевой лаборатории Министерства образования по увеличению нефтеотдачи пластов Института нефтегазового дела Северо-Восточного нефтяного университета.

Нажису, аспирант отделения нефтегазового дела Инженерной школы природных ресурсов Национального исследовательского Томского политехнического университета.

Ерофеев В.И., доктор технических наук, профессор отделения нефтегазового дела Инженерной школы природных ресурсов Национального исследовательского Томского политехнического университета.

$\boldsymbol{C y}$ Ченг, магистр ключевой лаборатории Министерства образования по увеличению нефтеотдачи пластов Института нефтегазового дела Северо-Восточного нефтяного университета.

Цзян Вэйдун, инженер Отдела разработки и производства.

Лу Сянго, доктор технических наук, профессор Института нефтегазового дела Северо-Восточного нефтяного университета. 
UDC 622.276

\section{STUDY ON SEEPAGE CHARACTERISTICS AND DISPLACEMENT EFFICIENCY OF WATER FLOODING IN OFFSHORE HEAVY OIL RESERVOIR}

Xie Kun1, xiekun725@163.com

Mei Jie ${ }^{1}$, sichuandexuesheng@163.com

Narisu², Narisu33@126.com

Vladimir I. Erofeev², erofeevvi@mail.ru

1 Northeast Petroleum University, 199, Razvitiya street, Daqing, 163000, China.

2 National Research Tomsk Polytechnic University, 30, Lenin avenue, Tomsk, 634050, Russia.

3 CNOOC Ltd. Beijing, 100010, China.
Su Cheng ${ }^{1}$, 380500259@qq.com

Jiang Weidong ${ }^{3}$, 1543284194@qq.com

Lu Xiangguo', 877459272@qq.com

The relevance. Compared with conventional reservoir, offshore heavy oil reservoir faced the problem of lower water flooding recovery. It is helpful to improve the water flooding recovery of heavy oil reservoir if we have more knowledge about seepage characteristics of water and oil. The main aim of the research is to investigate the change rule of seepage characteristics of water phase and oil phase in offshore heavy oil reservoir, which is helpful to the decision of field construction and can provide guidance for numerical simulation.

Methods. The reservoir geological characteristics, fluid properties and field construction technology of the destination offshore heavy oil reservoir in Bohai Oilfield were taken into consideration. The impact of core permeability, injection water washout and crude oil viscosity on relative permeability curve and displacement efficiency of water flooding were studied, through core displacement experiment using displacement method of unsteady state. The change of core inside structure is presented by core CT scanning and mercury pressure test. Results. With the increase of core permeability, water phase relative permeability increases, the swept volume of water phase becomes bigger, two-phase flow span gets wider, and ultimate recovery enhances. The function of "cleaning» and "erosion» that water washout exerts on core pore structure would enlarge the pore throat radius, increasing core permeability, and its influence on relative permeability curve and displacement efficiency is the same as the influence of permeability increase. With the crude oil viscosity increasing, mobility control ability of water gets weaker in the process of water flooding, displacement phase viscous fingering phenomenon aggravates, the swept volume of water phase becomes smaller, two-phase flow span gets narrower, and ultimate recovery decreases.

\section{Key words:}

Offshore oilfield, heavy oil reservoir, water flooding, relative permeability, unsteady state method, oil recovery.

This work was supported by the Natural Science Foundation of China (No. 51574086, 51834005), National science and technology major projects (2016 ZX05058-003-010), Postdoctoral Innovative Talents Support Program of China (BX20190065).

\section{REFERENCES}

1. Cao W., Xie K., Lu X., Liu Y., Zhang Y. Effect of profile-control oil-displacement agent on increasing oil recovery and its mechanism. Fuel, 2019, vol. 237, pp. 1151-1160.

2. Dai C., Yang S., Wu X., Liu Y., Peng D., Wang K., Wu Y. Investigation on Polymer Reutilization Mechanism of SaltTolerant Modified Starch on Offshore Oilfield. Energy \& Fuels, 2016, vol. 30, no. 7, pp. 5585-5592.

3. Xie K., Cao B., Lu X., Jiang W., Zhang Y., Li Q., Song K., Liu J. Wang W., Lv J., Na R. Matching between the diameter of the aggregates of hydrophobically associating polymers and reservoir porethroat size during polymer flooding in an offshore oilfield. Journal of petroleum science and engineering, 2019, vol. 177, pp. 558-569.

4. Narisu, Erofeev V.I., Lv J., Wang W. Study on filtration and rheological properties of polymer gel to improve oil recovery. Bulletin of the Tomsk Polytechnic University. Geo Assets Engineering, 2019, vol. 330, no. 3, pp. 147-157. In Rus.

5. Yu Y., Chang Z., Qi Y., Feng D. Research on new technology for offshore heavy oil thermal recovery with rod pumping. Journal of Petroleum Exploration \& Production Technology, 2018, vol. 8, no. 3, pp. 947-955.
6. Huang S., Cao M., Cheng L. Experimental study on the mechanism of enhanced oil recovery by multi-thermal fluid in offshore heavy oil. International Journal of Heat \& Mass Transfer, 2018, vol. 122, pp. 1074-1084.

7. Kim C., Lee J. Experimental study on the variation of relative permeability due to clay minerals in low salinity water-flooding. Journal of Petroleum Science and Engineering, 2017, vol. 157, pp. 292-304.

8. Su W., Liu Y., Gao Z., Yang L., Yang R., Mcharo W., Tang R. Relative permeability variations during low salinity water flooding in carbonate rocks with different mineral compositions. Journal of Dispersion Science and Technology, 2020, vol. 41, no. 2, pp. 227-234.

9. Narisu, Erofeev V.I., Lu X., Lv J., Wang X., Zhang L. The effect of layer water mineralization on physical chemical and filtration characteristics of polymeric solutions and gels for increasing oil recovery. Bulletin of the Tomsk Polytechnic University. Geo Assets Engineering, 2019, vol. 330, no. 4, pp. 136-145. In Rus.

10. Gong P., Liu B., Zhang J., Lv Z., Zhang G. Classification study on relative permeability curves. World Journal of Engineering and Technology, 2018, vol. 6, no. 4, pp. 723-737. 
11. Liu A., Wang K., Zang J., Du F., Zhou A. Relative permeability of gas for unconventional reservoirs. Transport in Porous Media, 2018, vol. 124, no. 1, pp. 289-307.

12. Zolotukhin A., Yazynina I., Shelyago E. Relative permeability hysteresis for oil-water system in hydrophilic rocks. Oil Industry Journal, 2016, no. 3, pp. 78-80.

13. Wang J., Huiqing L. A novel model and sensitivity analysis for viscoelastic polymer flooding in offshore oilfield. Journal of Industrial and Engineering Chemistry, 2014, vol. 20, no. 2, pp. 656-667.

14. Narisu, Erofeev V.I., Lu X., Tian Z., Zhang L. Optimization of parameters of inorganic profile control agent on the basis of sodium silicate for effective oil displacement from high salinity reservoir. Bulletin of the Tomsk Polytechnic University. Geo Assets Engineering, 2019, vol. 330, no. 11, pp. 59-68. In Rus.

15. Zhang J., Liu Z., Wang L., Fang Z., Deng J. The research and applications of remaining oil potential tapping in high watered stage for heavy oil reservoir in Bohai. Journal of Geoscience and Environment Protection, 2018, vol. 6, no. 9, pp. 10-21.

16. Yu Q., Lu X., Wang J., Guo Q., Niu L. Effects of the charge ions strength on the swelling of organic-inorganic nanogels. Bulletin of Korean Chemistry Society, 2016, vol. 37, no. 7, pp. 1124-1131.

\section{Information about the authors}

Xie Kun, Dr. Sc., associate professor, Northeast Petroleum University.

Mei Jie, graduate student, Northeast Petroleum University.

Narisu, post-graduate student, National Research Tomsk Polytechnic University.

Vladimir I. Erofeev, Dr. Sc., academician of RANS, professor, National Research Tomsk Polytechnic University.

Su Cheng, graduate student, Northeast Petroleum University.

Jiang Weidong, senior engineer, CNOOC Ltd.

Lu Xiangguo, Dr. Sc., professor, Northeast Petroleum University.
17. Xie K., Lu X., Pan H., Han D., Hu G., Zhang J., Zhang, B., Cao B. Analysis of dynamic imbibition effect of surfactant in microcracks of reservoir at high temperature and low permeability. SPE Production \&Operations, 2018, vol. 33, no. 3, pp. 596-606.

18. Wu S., Yan J., Zhao F. Effect of adsorption and deposition of asphaltines in crude oil on wettability and permeability of reservoir rocks. Shiyou Dахие Хиеbаo, 2004, vol. 28, no. 1, pp. 36-40.

19. Liu Z., Zheng Q., Tang Z., Zhang G. Effect of wettability on recovery and relative permeability. Oil \& Gas Geology, vol. 21, no. 2 , pp. $148-150$

20. Li J., Jiang H., Chen M., Gao H. Microscopic modelling of polymer flooding relative permeability curve and its influence factors, Journal of Southwest Petroleum University (Science \& Technology Edition), 2009, vol. 31, no. 4, pp. 122-126.

21. Guo L., Wang Y., Liu W., Zhang C., Liu W., Liu T. Variation law of reservoir parameters during water flooding in Dagang oilfield. Petroleum geology \& experiment, 2006, vol. 28, no. 1, pp. 86-91.

Received: 19 August 2020. 